\title{
Panorama da avaliação da Educação de Jovens e Adultos sob perspectivas da Educação Matemática
}

\author{
Adriano Vargas Freitas* \\ Célia Maria Carolino Pires ${ }^{* *}$
}

\begin{abstract}
Resumo
$\mathrm{O}$ artigo apresenta recorte de pesquisa desenvolvida no modelo de estado da arte, com foco em processos avaliativos na EJA sob perspectivas da Educação Matemática. A motivação central foi a verificação da necessidade de pesquisas que ajudem a melhorar o processo de ensino/aprendizagem da matemática dos alunos da EJA, e a percepção da importância de mapearmos produções existentes que orientem a comunidade de educadores matemáticos em suas investigações sobre o tema. Trabalhamos sob a metodologia da Análise Textual Discursiva na análise de produções publicadas no período de 2000 a 2011. Dentre os resultados, a verificação de que os desempenhos dos alunos em leitura e matemática estão fortemente correlacionados, e a defesa do desenvolvimento de formas avaliativas mais eficientes, que promovam a geração de informações que fomentem o debate sobre as temáticas envolvidas e contribuam para a formulação de novas políticas públicas educacionais, assim como a revisão das postas em prática.

Palavras-chave: educação de Jovens e Adultos; educação matemática; processos avaliativos.
\end{abstract}

\section{Evaluation of the panorama of Youth and Adult Education under perspectives of Mathematics Education}

\begin{abstract}
This article presents part of research carried out in state of the art model. We focus on evaluation processes in youth and adult education in the perspective of mathematics education. The main motivation was to verify the need for research to help improve the teaching and learning of mathematics in adult education. And also the perception of the importance of productions we mapped to guide the community of mathematics educators in their investigations on this topic. We worked with the methodology of Textual Analysis Discourse for the analysis published in production from 2000 to 2011. Among the results, we verified that the performance of students in reading and math are strongly correlated; we defend the development of more efficient evaluative forms, leading to the generation of information to encourage the debate on the issues involved, and contribute to the formulation of new educational policies, as well as a review of the implemented ones.

Keywords: youth and adult education; mathematics education; evaluative processes.
\end{abstract}

\section{Considerações iniciais}

$\mathrm{O}$ artigo apresenta um recorte de pesquisa desenvolvida no Programa de Estudos PósGraduados em Educação Matemática da PUC-SP, inserido na linha de pesquisa "A Matemática na Estrutura Curricular e Formação de Professores", em projeto denominado "O currículo de Matemática na Educação de Jovens e Adultos (EJA): dos intervenientes à prática em sala de aula". A motivação do projeto emergiu da experiência profissional de seus integrantes, da verificação da necessidade de pesquisas que ajudem a melhorar o processo de ensino/aprendizagem da matemática dos alunos nessa modalidade, e da percepção da importância de mapearmos as produções existentes e identificarmos possíveis lacunas que orientem a comunidade de educadores matemáticos em suas investigações sobre o tema.

\footnotetext{
*Endereço eletrônico: adrianovargas@id.uff.br

***Endereço eletrônico: ccarolinopires@gmail.com
}

No presente estudo elencamos resultados de pesquisas relacionadas a processos avaliativos da EJA, com foco especial sobre as contribuições que a Educação Matemática tem proporcionado ao tema e a esta modalidade de ensino como forma de (re)conhecimento da realidade histórica e atual dessa parcela de estudantes, que, ao retornarem aos bancos escolares têm por hábito se diferenciar dos demais grupos por apresentar de forma mais acentuada um comprometimento com a sua aprendizagem, e maiores necessidades de conhecer os motivos pelos quais devem aprender este ou aquele conteúdo.

Estamos falando de uma ação educativa dirigida a um sujeito de escolarização básica incompleta ou jamais iniciada e que acorre aos bancos escolares na idade adulta ou na juventude. A interrupção ou o 
impedimento de sua trajetória escolar não lhe ocorre, porém, apenas como um episódio isolado de não-acesso a um serviço, mas num contexto mais amplo, de exclusão social e cultural, e que, em grande medida, condicionará também as possibilidades de reinclusão que se forjarão nessa nova (ou primeira) oportunidade de escolarização. (FONSECA, 2007, p.15).

A Lei de Diretrizes e Bases (BRASIL, 1996), ao destacar a necessidade de ofertar educação básica a jovens e adultos, atentando-se para características e modalidades adequadas às necessidades e disponibilidade desse público, instigou a comunidade acadêmica a desenvolver investigações sobre a modalidade de ensino EJA. A publicação das Diretrizes Curriculares Nacionais para a Educação de Jovens e Adultos (BRASIL, 2001) e das orientações curriculares para primeiro e segundo segmento da EJA, em especial às recomendações para o ensino de Matemática (BRASIL, 2002a, 2002b), trouxeram contribuições às discussões sobre $\mathrm{o}$ ensino destinado a esse alunado, especialmente ao destacar que a EJA precisa ser concebida como um modelo pedagógico próprio, objetivando criar um ambiente propício a promover situações de aprendizagem que venham ao encontro das necessidades específicas de seus estudantes.

O saber matemático tem sido ressaltado como cada vez mais necessário em nossa contemporaneidade, caracterizada pela rápida evolução das tecnologias e meios de comunicação baseados muitas vezes em dados quantitativos e espaciais, em suas diferentes representações. Tal evolução torna cada vez mais complexa a vida cotidiana e também o mundo do trabalho, exigindo que as pessoas assimilem rapidamente um volume cada vez maior de informações e resolvam problemas utilizando pensamentos mais elaborados.

Diante dessas percepções, verificamos que o simples domínio da contagem e de técnicas de cálculo não têm sido mais suficientes para suprir todas as competências relacionadas às crescentes exigências culturais, econômicas e sociais do mundo moderno. Verificamos também que o processo educativo em EJA na área de matemática não deve estar mais calcado em práticas pedagógicas relacionadas apenas à memorização, ou à acumulação linear do saber, em que há rígidas hierarquias tomadas como base em um caminho pedagógico organizado do mais fácil para o mais complexo.

Ao moldarmos uma metodologia educacional diferenciada para a EJA, tendo por base as recomendações dos diferentes documentos e estudos da área, é importante adotar a concepção de que $\mathrm{o}$ jovem e o adulto reestruturam seus conhecimentos por meio das atividades que lhes são propostas (BRASIL, 2002a) e que, por isso, torna-se imprescindível que os erros matemáticos dos alunos passem a ser interpretados como manifestações desse processo de reestruturação e não mais como fracassos ou deficiências pessoais.

Nessa metodologia deve haver espaço para o diálogo como meio organizador do pensamento e atividades que estimulem a iniciativa pessoal, o trabalho coletivo, a autonomia e a criatividade do aluno, destacando de forma equilibrada procedimentos relativos ao pensamento geométrico, algébrico, numérico e ao raciocínio probabilístico e estatístico. Para que isso ocorra, encontramos indicações do uso de resolução de problemas, tecnologias (computador, internet, etc.), análise crítica da história da matemática, jogos, leituras de textos diversos (jornais, bulas de remédios, propagandas, etc.), destacando conhecimentos matemáticos nesses recursos, mas, ao mesmo tempo, e sempre que possível, apresentando-os de forma interdisciplinar e dialógica com as demais áreas de conhecimento.

As sugestões encontradas para o desenvolvimento dessas atividades focaram muitas vezes a adoção de "atividades sequenciais" e "projetos de trabalho" (BRASIL, 2002b, p.64) como bons recursos para o desenvolvimento de propostas que relacionem a matemática ao cotidiano do aluno e também a outras disciplinas, contribuindo para que sejam feitas conexões entre conhecimentos diversos e que sejam postas em prática uma organização curricular em rede (em contraposição à organização linear) e a avaliação de todo esse processo, entendida esta como parte fundamental de construção e reestruturação do conhecimento do aluno assim como orientadora das próprias práticas pedagógicas do professor.

Nesse contexto, em que a questão da especificidade de uma modalidade se confronta com objetivos comuns que ela precisa ter em relação à educação chamada regular, emergem muitas questões a ser respondidas por pesquisadores, sejam elas relativas a processos avaliativos (internos e externos ao ambiente escolar), sejam relativas a currículos, à formação de professores para atuar na EJA, a suas práticas em sala de aula, especialmente 
suas concepções e crenças quanto a ensinar matemática para a população de EJA.

O censo escolar brasileiro da educação básica realizado pelo Instituto Nacional de Estudos e Pesquisas Anísio Teixeira (INEP) nos informa que, das matrículas efetuadas no ano de 2013 nas escolas de ensino fundamental e médio brasileiras, na modalidade presencial, cerca de $8 \%$ foi na EJA. Mas verificou-se que nos últimos anos esse percentual vem apresentando queda, como podemos comprovar na Figura 1 a seguir.

Figura 1: Número de matrícula da EJA no Brasil, 2007 a 2013.

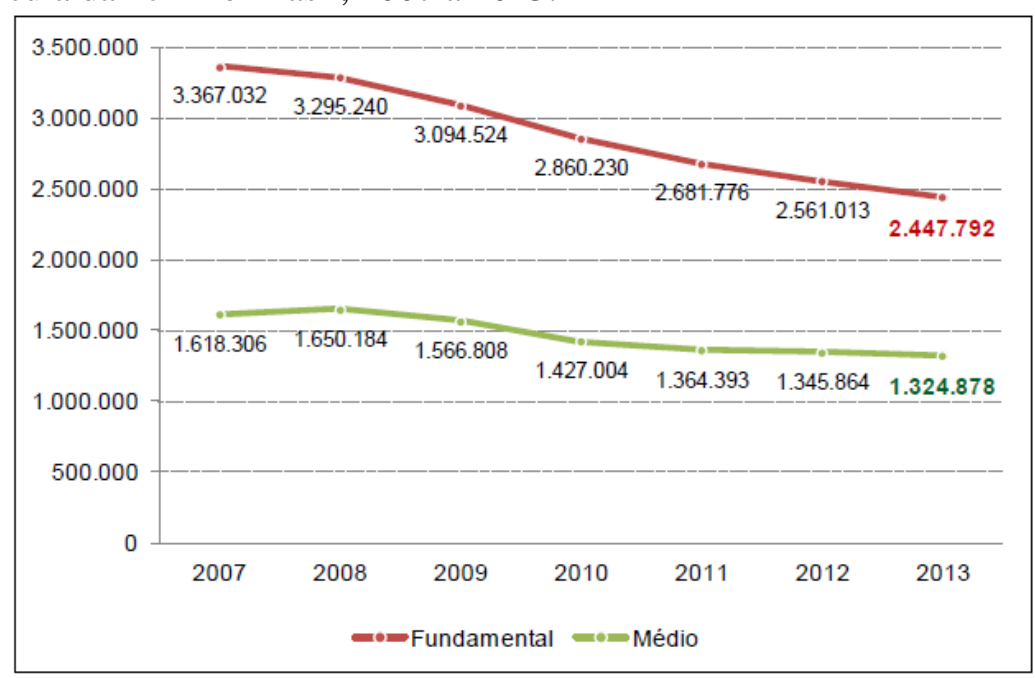

Fonte: INEP, MEC. Endereço:

http://portal.mec.gov.br/index.php?option=com_content $\&$ view $=$ article $\& i d=20264$.

Acesso em 07.06.2014.

A análise isolada de tais resultados pode ser interpretada, a princípio, como a proximidade do término da necessidade de oferta dessa modalidade de ensino, pois, devido ao constante declínio da quantidade de matrículas, conclusões apressadas induziriam ao entendimento de que estaríamos caminhando para o almejado momento na história da educação de nosso país em que todos os estudantes estivessem na escola, de acordo com a indicação mais propícia em relação à idade/série. Além disso, a análise em separado dessas quantificações poderia levar à errônea percepção de termos chegado também ao almejado fim do analfabetismo adulto.

Entretanto, ao verificar os números provenientes de outras estatísticas, percebemos que ainda estamos distantes da universalização da educação básica, pois, de acordo com os dados da Pesquisa Nacional por Amostra de Domicílios (PNAD), feita pelo Instituto Brasileiro de Geografia e Estatística (IBGE) em 2012 e divulgada nos últimos meses de 2013, o país ainda apresentava a expressiva taxa de $8,7 \%$ de analfabetismo, o que correspondia a cerca de 13,2 milhões de brasileiros analfabetos. Este resultado coloca o Brasil em $8^{\circ}$ lugar entre 150 países com maior número de analfabetos.

Importante destacarmos também que esses dados nos alertam para o fato de estarmos distantes inclusive do contexto latino americano, pois países como a Argentina e Chile apresentam taxas de analfabetismo consideradas apenas como residuais, ou seja, próximas de $3 \%$ da população.

\section{A pesquisa}

Nossa questão de estudo que desencadeou o processo de pesquisa qualitativa moldada em características de Estado da Arte foi: O que tem sido produzido e publicado sobre a Educação Matemática orientada para a Educação de Jovens e Adultos?

A opção por trabalharmos com a produção que envolve a Educação Matemática voltada para a EJA publicada no período de 2000 a 2011 em periódicos que façam parte da Listagem Qualis (CAPES-MEC) na área de Ensino de Ciências e Matemática, foi feita em função de buscar privilegiar a produção teórica que, por sua natureza, foi legitimada por bancas compostas por especialistas pertencentes aos quadros de avaliadores dos periódicos e que acabam por 
representar uma ampla fonte de dados a respeito das de pesquisas e, por vezes, do caráter inconcluso da relação ensino/aprendizagem, que, devido às suas especificidades e polissemia, requerem dos pesquisadores ampla cobertura sobre os fenômenos e as diversas interpretações envolvidos.

Do ponto de vista da relevância social e acadêmica, traçamos como objetivo de nosso estudo a construção de material que possa referenciar discussões sobre o tema, assim como reflexões e o redimensionamento teórico-prático de projetos políticos pedagógicos relacionados à $\mathrm{EJA}$, em especial na área de Educação Matemática. Buscar conhecer o já construído para, a partir desse conhecimento, analisar possíveis pontos de convergência e divergência, lacunas, consequências sociais e políticas, contribuições, divergências, generalizações e perspectivas para os futuros tempos foi o que nos convenceu a optar pelo desenvolvimento desta pesquisa. Para a sua realização, delimitamos os periódicos que iriam fazer parte de nossa coleta de dados da seguinte forma: (a) seriam analisados os periódicos pertencentes à listagem Qualis, classificados por A1, A2, B1, B2, B3, B4 ou B5, sendo excluídos, desta forma, apenas os de classificação $\mathrm{C}$; (b) o período analisado de publicações nesses periódicos se iniciaria em janeiro de 2000 e iria até julho de 2011; e (c) seriam analisadas as edições dos periódicos que estivessem disponibilizadas de forma completa (o texto na íntegra), e gratuita, no ambiente virtual da internet.

Iniciamos com um total de 15.828 artigos. Mas, ainda nesta etapa, verificamos a pouca quantidade de produções encontradas que fossem voltadas especificamente para a educação matemática na EJA, daí a opção de ampliarmos para produções que focassem, mesmo que de forma indireta, nossa questão de estudo. Nessa opção, abrimos espaço para ouvir vozes de educadores de outras áreas, mas que, em suas produções, envolviam o processo de ensino e aprendizagem da matemática, formação do professor, currículos de matemática, ou outros tópicos a eles relacionados.

Após análises e leituras iniciais, chegamos à seleção de 135 artigos para o nosso estado da arte. Estas produções foram classificadas dentro de quatro temas: I) Formação/Atuação do Professor/Alfabetizador da EJA; (II) Práticas Pedagógicas na EJA; III) Currículo da EJA; e IV) Avaliação da/na EJA. Neste artigo focamos o tema IV. A figura 2 apresenta a distribuição desses artigos de acordo com os temas.

Figura 2: Quantidade de artigos distribuídos por temas de análise.

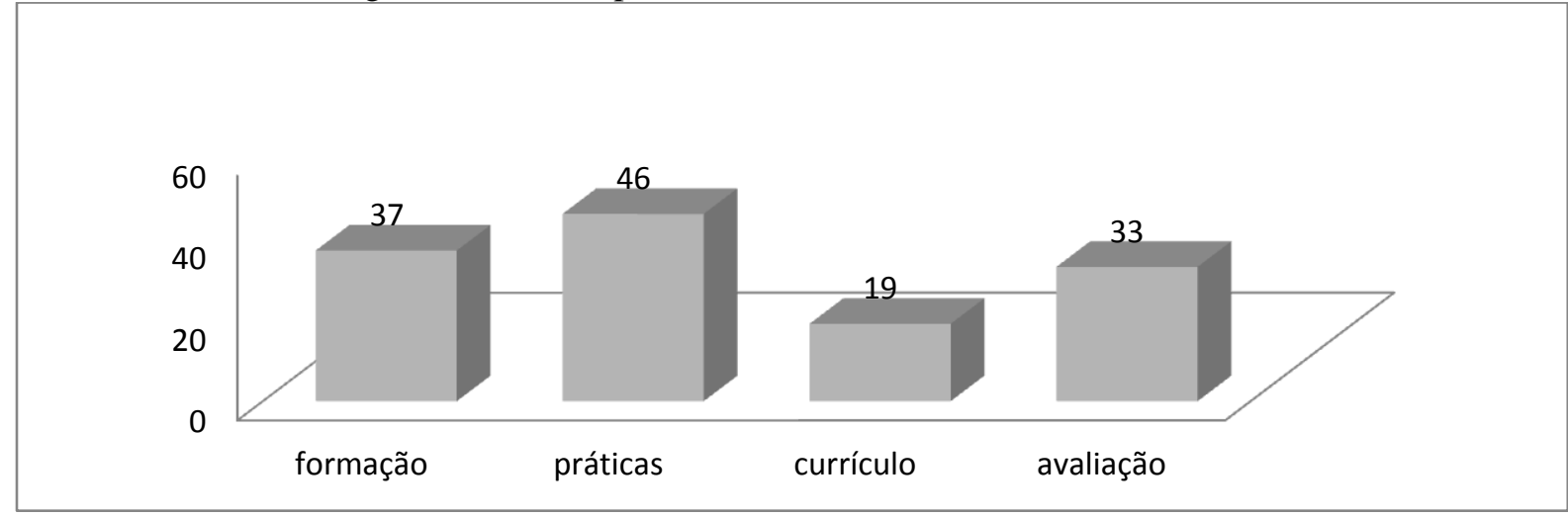

Fonte: Dados coletados e organizados pelos autores.

Para a fase de análise dos textos, e posterior construção do metatexto, utilizamos a Análise Textual Discursiva (ATD), cujas características propiciam uma pesquisa qualitativa envolvendo análises criteriosas de textos diversos, e, a partir daí, a compreensão dos fenômenos investigados. Para isso, tomamos como base os estudos de Moraes (2003), e Moraes e Galiazzi (2006; 2011).

\section{O que nos informam os artigos}

No nosso entendimento, a avaliação é um processo político a serviço da sociedade na busca do aperfeiçoamento da educação e do pleno desenvolvimento do cidadão. (FERRARI, 2007, p.146).

As 33 produções analisadas no tema "avaliação da/na EJA" envolveram um total de 41 autores/pesquisadores, sendo 34 deles ligados a 
instituições de ensino de nível superior (e/ou pósgraduação), 1 ao ensino do nível básico, 4 ao INEP e 2 a ONG's. Dos 34 autores que trabalham em cursos de graduação ou pós-graduação, 7 atuam em instituições estrangeiras (Argentina, Chile, México, Portugal, Hungria e Romênia) e, dentre os 27 que atuam em instituições nacionais, apenas 8 estão vinculados a instituições particulares, os demais a instituições públicas $(10$ dessas instituições localizam-se na região Sudeste, 6 na região Sul e 1 na região Nordeste).

A tabela 1 apresenta as referências dos artigos selecionados para o tema em questão.

Tabela 1: Artigos selecionados no tema IV - Avaliação da/na EJA.

\begin{tabular}{|c|c|c|c|}
\hline \multirow[t]{2}{*}{$\mathbf{N}^{0}$} & \multicolumn{3}{|c|}{ Referências } \\
\hline & Título & Autor(es) & Periódico, volume, ano \\
\hline 1 & $\begin{array}{l}\text { Mulheres, homens e matemática: uma leitura a partir dos } \\
\text { dados do Indicador Nacional de Alfabetismo Funcional }\end{array}$ & $\begin{array}{l}\text { SOUZA, M. C. R. F., e } \\
\text { FONSECA, M. C. F. R. }\end{array}$ & $\begin{array}{l}\text { Educação e Pesquisa, } \\
\text { v34, n3, } 2008 .\end{array}$ \\
\hline 2 & $\begin{array}{l}\text { Construção de escala combinada para a medição do } \\
\text { alfabetismo em contexto não escolar }\end{array}$ & $\begin{array}{l}\text { RIBEIRO, V. M., e } \\
\text { SOARES, T. M. }\end{array}$ & $\begin{array}{l}\text { Estudos em Avaliação } \\
\text { Educacional, v19, n41, } \\
\text { 2008. }\end{array}$ \\
\hline 3 & $\begin{array}{l}\text { Acerca del dominio del código de la escritura em América } \\
\text { Latina y su relación conlos desafios actuales: conclusiones } \\
\text { de uma investigación em siete países de América Latina }\end{array}$ & INFANTE, M. I. & $\begin{array}{l}\text { Educação \& Sociedade, } \\
\text { v23, n81, } 2002 .\end{array}$ \\
\hline 4 & $\begin{array}{l}\text { "Programa Alfabetização Solidária": terceirização no } \\
\text { contexto da Reforma do Estado }\end{array}$ & $\begin{array}{l}\text { BARREYRO, } \\
\text { G. B. O. }\end{array}$ & $\begin{array}{l}\text { Educar em Revista, n38, } \\
2010 .\end{array}$ \\
\hline 5 & $\begin{array}{l}\text { Políticas públicas para educação de jovens e adultos no } \\
\text { Brasil: a permanente (re)construção da subalternidade - } \\
\text { considerações sobre os Programas Brasil Alfabetizado e } \\
\text { Fazendo Escola }\end{array}$ & $\begin{array}{l}\text { RUMMERT, S. M., e } \\
\text { VENTURA, J. P. }\end{array}$ & $\begin{array}{l}\text { Educar em Revista, n29, } \\
2007 .\end{array}$ \\
\hline 6 & $\begin{array}{l}\text { Descentralização, focalização e parceria: uma análise das } \\
\text { tendências nas políticas públicas de educação de jovens e } \\
\text { adultos }\end{array}$ & DI PIERRO, M. C. & $\begin{array}{l}\text { Educação e Pesquisa, } \\
\text { v27, n2, } 2001 .\end{array}$ \\
\hline 7 & $\begin{array}{l}\text { "marca social" da educação de jovens e adultos } \\
\text { trabalhadores }\end{array}$ & $\begin{array}{l}\text { RUMMERT, } \\
\text { S. M. A. }\end{array}$ & $\begin{array}{l}\text { Trabalho \& Educação, } \\
2008 .\end{array}$ \\
\hline 8 & $\begin{array}{l}\text { Leitura comparativa de campanha de alfabetização cubana } \\
\text { com a de alfabetização da Guiné-Bissau }\end{array}$ & CÁ, L.O. & $\begin{array}{l}\text { ETD - Educação } \\
\text { Temática Digital, V3, } \\
\text { N2, } 2002 .\end{array}$ \\
\hline 9 & $\begin{array}{l}\text { A relação dos técnicos de educação de adultos com o } \\
\text { discurso pedagógico oficial: um caso à norte de Portugal }\end{array}$ & $\begin{array}{l}\text { LOUREIRO, A. P. F., e } \\
\text { CRISTÓVÃO, A. F. A. } \\
\text { C. A }\end{array}$ & $\begin{array}{l}\text { Educação \& Sociedade, } \\
\text { v29, n105, } 2008 .\end{array}$ \\
\hline 10 & $\begin{array}{l}\text { Educação de jovens e adultos na América Latina e Caribe: } \\
\text { trajetória recente }\end{array}$ & DI PIERRO, M. C. & $\begin{array}{l}\text { Cadernos de Pesquisa } \\
\text { (F.C.C.), v38, n134. } \\
\text { 2008. }\end{array}$ \\
\hline 11 & $\begin{array}{l}\text { Vantagens da alfabetização na perspectiva de adultos } \\
\text { residentes em áreas rurais do Brasil e de Portugal }\end{array}$ & $\begin{array}{c}\text { FILHO, E. A., e } \\
\text { SALCIDES, A. M. F. }\end{array}$ & $\begin{array}{l}\text { Cadernos da História da } \\
\text { Educação (UFU), n6, } \\
2007 .\end{array}$ \\
\hline 12 & $\begin{array}{l}\text { O Plano nacional de Educação e a Educação de Jovens e } \\
\text { Adultos no estado do Paraná }\end{array}$ & $\begin{array}{l}\text { MASCHIO, E. F.; } \\
\text { PRADO, E. M., e } \\
\text { SOUZA, M. A. }\end{array}$ & $\begin{array}{l}\text { Olhar de Professor, } \\
\text { v12(1), } 2009 .\end{array}$ \\
\hline 13 & Um olhar sobre os indicadores de analfabetismo no Brasil & $\begin{array}{l}\text { PINTO, J. M. R., } \\
\text { BRANT, L. L. N. A. O., } \\
\text { SAMPAIO, C. E. M, e } \\
\text { PASCOM, A. R. P. }\end{array}$ & $\begin{array}{l}\text { Revista Brasileira de } \\
\text { Estudos Pedagógicos } \\
\text { INEP, v81, n199, } 2000 .\end{array}$ \\
\hline 14 & $\begin{array}{l}\text { Tramando concepções e sentidos para redizer o direito à } \\
\text { educação de jovens e adultos }\end{array}$ & PAIVA, J. & $\begin{array}{l}\text { Revista Brasileira de } \\
\text { Educação ANPED, v11, } \\
\text { n33, 2006. }\end{array}$ \\
\hline 15 & A ação de governos locais na educação de jovens e adultos & HADDAD, $\mathrm{S}$. & $\begin{array}{l}\text { Revista Brasileira de } \\
\text { Educação ANPED, v12, } \\
\text { n35, 2007. }\end{array}$ \\
\hline
\end{tabular}




\begin{tabular}{|c|c|c|c|}
\hline 16 & $\begin{array}{l}\text { Modelo e critérios de evaluación de materiales y contenidos } \\
\text { de alfabetización y primaria para adultos }\end{array}$ & SERVIN, M. A. & $\begin{array}{l}\text { Revista Mexicana de } \\
\text { Investigación Educativa, } \\
\text { v5, n9, 2000. }\end{array}$ \\
\hline 17 & $\begin{array}{l}\text { Letramento no Brasil: alguns resultados do indicador } \\
\text { nacional de alfabetismo funcional }\end{array}$ & $\begin{array}{l}\text { RIBEIRO, V. M., } \\
\text { VÓVIO, C. L., e } \\
\text { MOURA, M. P }\end{array}$ & $\begin{array}{l}\text { Educação \& Sociedade, } \\
\text { v23, n81, } 2002 .\end{array}$ \\
\hline 18 & $\begin{array}{l}\text { Analfabetismo e níveis de letramento no Brasil: o que dizem } \\
\text { os censos? }\end{array}$ & FERRARO, A. R & $\begin{array}{l}\text { Educação \& Sociedade, } \\
\text { v23, n81, } 2002 .\end{array}$ \\
\hline 19 & $\begin{array}{l}\text { Avaliação dos estudantes do PROEJA: em busca da } \\
\text { inovação }\end{array}$ & FERRARI, C. R. & $\begin{array}{l}\text { Cadernos FAPA, número } \\
\text { especial, } 2007 .\end{array}$ \\
\hline 20 & $\begin{array}{l}\text { Questões em torno da construção de indicadores de } \\
\text { analfabetismo e letramento }\end{array}$ & RIBEIRO, V. M. & $\begin{array}{l}\text { Educação e Pesquisa } \\
\text { (USP), v27, n2, } 2001 .\end{array}$ \\
\hline 21 & $\begin{array}{l}\text { Educação de adultos na educação ao longo da vida: } \\
\text { desenvolvimentos atuais e interdependentes na Alemanha e } \\
\text { na Europa, a caminho da VI CONFINTEA }\end{array}$ & HINZEN, $\mathrm{H}$. & $\begin{array}{c}\text { Revista Brasileira de } \\
\text { Educação ANPED, v14, } \\
\text { n41, } 2009 .\end{array}$ \\
\hline 22 & $\begin{array}{l}\text { Evolução recente da educação de pessoas adultas na } \\
\text { Espanha }\end{array}$ & DI PIERRO, M. C. & $\begin{array}{l}\text { Educação \& Sociedade, } \\
\text { ano XXI, n72, } 2000 .\end{array}$ \\
\hline 23 & $\begin{array}{l}\text { EJA, Trabalho e Educação na Formação profissional: } \\
\text { possibilidades e limites }\end{array}$ & $\begin{array}{l}\text { FURTADO, E. D. P., e } \\
\text { LIMA, K. R. R. }\end{array}$ & $\begin{array}{l}\text { Educação e Realidade, } \\
\text { v35(1), } 2010 .\end{array}$ \\
\hline 24 & $\begin{array}{l}\text { Tensões, contradições e avanços: a educação de jovens e } \\
\text { adultos em uma escola municipal de Belo Horizonte }\end{array}$ & $\begin{array}{l}\text { SOARES, L., e } \\
\text { VENÂNCIO, A. R. }\end{array}$ & $\begin{array}{l}\text { Educar em Revista, n29, } \\
2007 .\end{array}$ \\
\hline 25 & $\begin{array}{l}\text { Educação e trabalho: reflexões sobre a proposta do } \\
\text { Programa Nacional de Integração da Educação profissional } \\
\text { com a Educação básica na modalidade de Educação de } \\
\text { Jovens e Adultos - PROEJA }\end{array}$ & PORTELA, J. L. & $\begin{array}{l}\text { Trabalho \& Educação, } \\
\text { v18, n2, } 2009 \text {. }\end{array}$ \\
\hline 26 & $\begin{array}{l}\text { O PROEJA em Construção: enfrentando desafios políticos e } \\
\text { pedagógicos }\end{array}$ & FILHO, D. L. L. & $\begin{array}{l}\text { Educação e Realidade, } \\
\text { v35(1), } 2010 .\end{array}$ \\
\hline 27 & $\begin{array}{l}\text { A educação de Jovens e adultos no Plano Nacional de } \\
\text { Educação: avaliação, desafios e perspectivas }\end{array}$ & DI PIERRO, M. C. & $\begin{array}{l}\text { Educação \& Sociedade, } \\
\text { v31, n112, } 2010 .\end{array}$ \\
\hline 28 & $\begin{array}{l}\text { Jovens e adultos trabalhadores pouco escolarizados no Brasil } \\
\text { e em Portugal: alvos da mesma lógica de conformidade }\end{array}$ & $\begin{array}{l}\text { RUMMERT, S. M., e } \\
\text { ALVES, N. }\end{array}$ & $\begin{array}{c}\text { Revista Brasileira de } \\
\text { Educação ANPED, v15, } \\
\text { n45, } 2010 .\end{array}$ \\
\hline 29 & $\begin{array}{l}\text { Balanço da produção de conhecimentos sobre educação não } \\
\text { escolar de adultos: PLANFOR e educação do trabalhador, } \\
\text { 1999-2006 }\end{array}$ & TARTUCE, G. L. B. P. & $\begin{array}{l}\text { Revista e-Curriculum } \\
\text { (PUC-SP), v5, n1, } 2009 .\end{array}$ \\
\hline 30 & $\begin{array}{l}\text { A política educacional do PROEJA e o atendimento das } \\
\text { demandas econômicas e sociais }\end{array}$ & HOTZ, K. G. & $\begin{array}{l}\text { Trabalho \& Educação, } \\
\text { v19, n1, } 2010 .\end{array}$ \\
\hline 31 & $\begin{array}{l}\text { A educação de jovens e adultos no Brasil: um campo } \\
\text { político pedagógico em disputa }\end{array}$ & $\begin{array}{l}\text { BAQUERO, R. V. A., e } \\
\text { FISHER, M. C. B. }\end{array}$ & $\begin{array}{l}\text { Educação UNISINOS, } \\
\text { v5, n9, } 2004 .\end{array}$ \\
\hline 32 & $\begin{array}{l}\text { Educação de jovens e adultos na América Latina: políticas } \\
\text { de melhoria ou de transformação; reflexões com vistas à VI } \\
\text { CONFINTEA }\end{array}$ & RODRIGUEZ, L. M. & $\begin{array}{c}\text { Revista Brasileira de } \\
\text { Educação ANPED, v14, } \\
\text { n41, } 2009 .\end{array}$ \\
\hline 33 & $\begin{array}{l}\text { A participação da sociedade civil brasileira na educação de } \\
\text { jovens e adultos e na CONFINTEA VI }\end{array}$ & HADDAD, S. & $\begin{array}{l}\text { Revista Brasileira de } \\
\text { Educação ANPED, v14, } \\
\text { n41, } 2009 .\end{array}$ \\
\hline
\end{tabular}

Fonte: Dados coletados e organizados pelos autores.

De uma forma geral, as produções tomaram por base pesquisas do tipo qualitativo, tendo sobressaído a forma de coleta de dados via revisão bibliográfica. Quanto a esse ponto, inclusive, destacamos a grande utilização nesses artigos de dados quantitativos provenientes de censos, de outras pesquisas e também via processos de avaliação aplicados a docentes e estudantes.
Destacamos também o fato de que, embora tenhamos buscado analisar pesquisas que envolvessem processos avaliativos no interior dos ambientes educacionais onde se desenvolve o processo ensino/aprendizagem da EJA, encontramos basicamente resultados e reflexões sobre processos externos e globais.

Verificamos grande ênfase dada às questões 
histórico-político-sociais relacionadas à educação de jovens e adultos que foram delineadas nas últimas décadas e que culminaram nos alarmantes atuais índices de analfabetos e analfabetos funcionais. Diversos estudos apontaram o crescente entendimento a respeito da educação como um direito (RODRIGUEZ, 2009; DI PIERRO, 2010) e buscaram revelar e analisar informações a respeito da dura realidade dos indivíduos que querem retornar aos estudos e desejam melhorias de condições sociais e trabalhistas. Essa, por sinal, aparece como uma das grandes motivações para frequentar novamente os estudos (PAIVA, 2006; HADDAD, 2009; PORTELA, 2009; TARTUCE, 2009; FILHO, 2010; HOTZ, 2010).

Em diferentes pesquisas, a constatação de que, de uma forma geral, o aluno que recorre a esses cursos pertence à classe popular, é pobre, muitas vezes habita assentamentos urbanos precários e sobrevive de trabalhos pouco qualificados da economia informal (FILHO e SALCIDES, 2007; DI PIERRO, 2008; RUMMERT, 2008). No Brasil, em linhas gerais, dos analfabetos quase a totalidade pertence às classes $\mathrm{D}$ e $\mathrm{E}$, moram em municípios do interior e não possuem qualquer escolaridade (RIBEIRO, VÓVIO e MOURA, 2002). Nessas produções, as reflexões históricas, políticas e sociais quase sempre denunciam a existência de milhões de cidadãos ainda marcados pelo estigma de não dominarem a leitura, a escrita e os cálculos básicos, e que essa forma extrema de exclusão educacional é geralmente secundada por outras formas de exclusão social.

Tidas por alguns estudos como subordinadas à lógica de reorganização do capital, as propostas relacionadas à ampliação dos níveis de escolaridade envolvidas na EJA têm servido no Brasil basicamente para a qualificação de força de trabalho para o exercício de trabalhos simples (RUMMERT e VENTURA, 2007; RUMMERT, 2008, PORTELA, 2009; HOTZ, 2010; RUMMERT e ALVES, 2010).

Ao avaliar os resultados de antigos e recentes projetos educacionais direcionados à EJA no Brasil, estudos destacam a tendência à municipalização e segmentação dessa modalidade de ensino, assim como a participação da sociedade civil e os novos papéis do Estado (RIBEIRO, VÓVIO e MOURA, 2002; HADDAD, 2007; RUMMERT e VENTURA, 2007; MASCHIO, PRADO e SOUZA, 2009; BARREYRO, 2010; DI PIERRO, 2001, 2010; FURTADO e LIMA, 2010; RUMMERT e ALVES, 2010). Uma das hipóteses defendidas é a de que o recuo do Estado no financiamento e na oferta dos serviços sociais ocorrido durante décadas gerou certo deslocamento da fronteira entre o público e o privado que, encampados pela denominação de parceria, acabou por envolver e responsabilizar a sociedade civil por tarefas até então entendidas como específicas dos governos, como no caso da oferta da EJA.

Tais análises geraram outros importantes pontos de convergência, como a defesa da necessidade de desenvolvimento de formas avaliativas mais eficientes em EJA, além da construção de indicadores de alfabetização/letramento, que gerem informações que possam fomentar o debate público sobre as temáticas envolvidas e contribuir para a formulação de novas políticas públicas educacionais, assim como a revisão das políticas já postas em prática.

Com relação às análises provenientes de avaliações de projetos já em andamento em nosso país, destacou-se a verificação da grave situação de uma grande parcela da população brasileira ainda se encontrar em condição de analfabetismo absoluto, além do crescente contingente dos novos analfabetos funcionais.

Importante destacarmos o entendimento, neste nosso estudo, de alfabetismo/letramento como a capacidade de compreender, utilizar e julgar informações escritas em materiais diversos (textos contínuos, gráficos, tabelas, anúncios, etc.), assim como sua importância em EJA como forma de ampliar os conhecimentos do indivíduo e proporcionar sua participação na sociedade (SOUZA e FONSECA, 2008; RIBEIRO e SOARES, 2008). Essa concepção supera ideias dicotômicas anteriores de que a leitura pertence somente à disciplina de língua portuguesa ou dos números como assunto exclusivo da matemática. Diversos estudos, tais como o de Ribeiro e Soares (2008), inclusive, reiteraram a verificação de que os desempenhos do aluno de EJA em leitura e matemática estão fortemente correlacionados (RIBEIRO e SOARES, 2008).

Foram encontrados poucos pontos de análise que se apresentassem orientados à avaliação da EJA diretamente na área de matemática. Entretanto, por muitas vezes destacou-se nas produções o fato de essa área ser considerada pelos professores e alunos como a que representa as maiores dificuldades relacionadas ao processo de ensino e aprendizagem dessa modalidade de ensino e que, por isso, quase sempre se torna um fator de influência sobre a permanência ou evasão do aluno 
jovem ou adulto na escola (RIBEIRO, VÓVIO e MOURA, 2002; INFANTE, 2002).

Estudos defenderam a importância de avaliações realizadas periodicamente, tanto do tipo internas quanto do tipo externas - avaliação entendida como ferramenta imprescindível para definição de dimensões cognitivas, sociais, definição de metodologias, custos, etc. (RODRIGUEZ, 2009). Entretanto, esses estudos concluem que a avaliação por si só não garante a eficácia e nem mesmo a eficiência do processo escolar.

Com a mesma ênfase, foi ressaltado o entendimento de que as séries fundamentais da EJA não têm sido suficientes para que o estudante alcance níveis apropriados de leitura compreensiva de textos e documentos, assim como de domínio de cálculos matemáticos elementares (INFANTE, 2002; RIBEIRO, VÓVIO e MOURA, 2002). Daí a defesa da ampliação desse tempo no ambiente escolar, e da necessidade de que a educação tenha um caráter permanente.

\section{Em busca de caminhos que apontem soluções}

No imaginário de diversas pessoas, ligadas ou não à educação, a matemática na EJA é quase um luxo cujo acesso ainda se reveste de grandes percalços impeditivos. Afinal, dizem em argumentos mais imediatistas, aos alunos dessa modalidade devem ser oferecidas formas de acesso às oportunidades de nossa sociedade e formas de desenvolvimento de habilidades voltadas para a busca de sua cidadania plena. Entretanto, como verificamos em nosso estado da arte, ainda pouco se tem enfatizado que na atual sociedade, cada vez mais tecnológica, o acesso ao conhecimento pode ser um excelente caminho, primeiramente para a percepção da sua condição nessa sociedade e, posteriormente, para a busca e a exigência de seus direitos de cidadão, assim como o reconhecimento dos direitos de seus semelhantes.

Em outras palavras, é imprescindível que o discurso pela defesa da cidadania do estudante da EJA esteja sempre acompanhado do argumento de que a ele não pode ser oferecida uma educação menor, resumida ou aligeirada. Por outro lado, entendemos que essa educação não deva ser do tipo enciclopédico, ou distante da cultura na qual esteja inserido $o$ aluno, que traz consigo vivências envolvendo a utilização de conhecimentos dessa área, mas que, ao mesmo tempo, muitas vezes ainda a enxerga como uma das áreas mais inacessíveis.
Consideramos que a pouca quantidade de estudos realizados sobre a Educação Matemática na EJA, assim como da pouca quantidade de estudos voltados para a avaliação de conhecimentos matemáticos nesta mesma modalidade de ensino, em especial na sala de aula, talvez seja fruto do tardio reconhecimento da própria EJA como modalidade de ensino, ou por ainda podermos considerar como jovem a área da Educação Matemática e, por isso, ter muitas das suas pesquisas voltadas para as séries regulares. Ponderamos que o conjunto de todos esses e outros possíveis fatores não elencados têm resultado em certo esquecimento dessa grande parcela de estudantes que retornam às escolas, dos professores que atuam nessa modalidade e do processo de ensino e aprendizagem que nessa conjunção se realiza.

Mas não podemos ignorar, e aí ressaltamos nossa concordância com uma grande quantidade de autores/pesquisadores destacados em nosso estudo, que, pelas especificidades que envolvem a EJA e o caráter heterogêneo de seus alunos, as respostas prontas e generalistas talvez não se apliquem a ela.

Entretanto, sem considerarmos uma contradição, ao analisar a área específica de matemática, concluímos que alguma generalização, como, por exemplo, na indicação de conteúdos essenciais a serem desenvolvidos pedagogicamente, pode vir a ser uma forma de buscar garantir aos estudantes uma melhor qualidade em seus cursos, uma melhor preparação para as etapas seguintes de escolaridade e, por consequência, um aumento no sentimento de autoeficácia e pertencimento a uma sociedade que deles exige cada vez mais rapidez na assimilação e análise de informações de todos os tipos, e em muitos momentos de suas vidas.

\section{Referências Bibliográficas}

BARREYRO, G. B. O "Programa Alfabetização Solidária": terceirização no contexto da Reforma do Estado. Educar em Revista, n.38, 2010.

BRASIL. Lei de Diretrizes e Bases da Educação: Lei 9.394. Diário Oficial da União. Brasília, DF, 1996.

BRASIL. Educação para jovens e adultos: ensino fundamental: proposta curricular - $\mathbf{1}^{\circ}$ segmento. São Paulo: Ação Educativa; Brasília: MEC, 2001. 
BRASIL. Proposta Curricular para a educação de jovens e adultos: segundo segmento do ensino fundamental: 5a a 8a série. Vol.1. Secretaria de Educação Fundamental, Brasília: MEC, 2002(a).

BRASIL. Proposta Curricular para a educação de jovens e adultos: segundo segmento do ensino fundamental: 5a a 8a série. Matemática, Ciências, Arte e Educação Física. Vol.3. Secretaria de Educação Fundamental, Brasília: MEC, 2002.(b).

DI PIERRO, M. C. Descentralização, focalização e parceria: uma análise das tendências nas políticas públicas de educação de jovens e adultos. Educação e Pesquisa, v27, n2, 2001.

DI PIERRO, M. C. Educação de jovens e adultos na América Latina e Caribe: trajetória recente. Cadernos de Pesquisa (F.C.C.), v38, n134. 2008.

DI PIERRO, M. C. A educação de Jovens e adultos no Plano Nacional de Educação: avaliação, desafios e perspectivas. Educação \& Sociedade, v31, n112, 2010.

FERRARI, C. R. Avaliação dos estudantes do PROEJA: em busca da inovação. Cadernos FAPA, número especial, 2007.

FILHO, D. L. L. O PROEJA em Construção: enfrentando desafios políticos e pedagógicos. Educação e Realidade, v35(1), 2010.

FILHO, E. A., e SALCIDES, A. M. F. Vantagens da alfabetização na perspectiva de adultos residentes em áreas rurais do Brasil e de Portugal. Cadernos da História da Educação (UFU), n6, 2007.

FONSECA, Maria da Conceição F.R. Educação Matemática de Jovens e Adultos. $2^{\mathrm{a}}$ edição: Autêntica. Belo Horizonte, MG. 2007.

FURTADO, E. D. P., e LIMA, K. R. R. EJA, Trabalho e Educação na Formação profissional: possibilidades e limites. Educação e Realidade, v35(1), 2010.

HADDAD, S. A ação de governos locais na educação de jovens e adultos. Revista Brasileira de Educação ANPED, v12, n35, 2007.

HADDAD, S. A participação da sociedade civil brasileira na educação de jovens e adultos e na CONFINTEA VI. Revista Brasileira de Educação ANPED, v14, n41, 2009.

HOTZ, K. G. A política educacional do PROEJA e o atendimento das demandas econômicas e sociais. Trabalho \& Educação, v19, n1, 2010.

INFANTE, M. I. Acerca del dominio del código de la escritura em América Latina y su relación con los desafios actuales: conclusiones de uma investigación em siete países de América Latina. Educação \& Sociedade, v23, n81, 2002.

MASCHIO, E. F.; PRADO, E. M., e SOUZA, M. A. O Plano nacional de Educação e a Educação de Jovens e Adultos no estado do Paraná. Olhar de Professor, v12(1), 2009.

MORAES, Roque. Uma tempestade de luz: a compreensão possibilitada pela análise textual discursiva. Ciência e Educação. V.9, n.2, p.191211, 2003. Disponível em: <http://www.scielo.br/pdf/ciedu/v9n2/04.pdf>. Acesso em 20 de fevereiro de 2012.

MORAES, Roque. GALIAZZI, Maria do Carmo. Análise textual discursiva: processo reconstrutivo de múltiplas faces. Ciência e Educação. V.12, n.1, p.117-128, 2006. Disponível em: <http://www.scielo.br/pdf/ciedu/v12n1/08.pdf >.

Acesso em 20 de fevereiro de 2012.

MORAES, Roque. GALIAZZI, Maria do Carmo. Análise textual discursiva. $2^{\mathrm{a}}$ Ed. Rio Grande do Sul: Unijuí, 2011.

PAIVA, J. Tramando concepções e sentidos para redizer o direito à educação de jovens e adultos. Revista Brasileira de Educação ANPED, v11, n33, 2006.

PORTELA, J. L. Educação e trabalho: reflexões sobre a proposta do Programa Nacional de Integração da Educação profissional com a Educação básica na modalidade de Educação de Jovens e Adultos - PROEJA. Trabalho \& Educação, v18, n2, 2009.

RIBEIRO, V. M., e SOARES, T. M. Construção de escala combinada para a medição do alfabetismo em contexto não escolar. Estudos em Avaliação Educacional, v19, n41, 2008. 
RIBEIRO, V. M., VÓVIO, C. L., e MOURA, M. P. Letramento no Brasil: alguns resultados do indicador nacional de alfabetismo funcional. Educação \& Sociedade, v23, n81, 2002.

RODRIGUEZ, L. M. Educação de jovens e adultos na América Latina: políticas de melhoria ou de transformação; reflexões com vistas à VI CONFINTEA. Revista Brasileira de Educação ANPED, v14, n41, 2009.

RUMMERT, S. M. A "marca social” da educação de jovens e adultos trabalhadores. Trabalho \& Educação, 2008.

RUMMERT, S. M., e ALVES, N. Jovens e adultos trabalhadores pouco escolarizados no Brasil e em Portugal: alvos da mesma lógica de conformidade. Revista Brasileira de Educação ANPED, v15, n45, 2010.
RUMMERT, S. M., e VENTURA, J. P. Políticas públicas para educação de jovens e adultos no Brasil: a permanente (re)construção da subalternidade - considerações sobre os Programas Brasil Alfabetizado e Fazendo Escola. Educar em Revista, n29, 2007.

SOUZA, M. C. R. F., e FONSECA, M. C. F. R. Mulheres, homens e matemática: uma leitura a partir dos dados do Indicador Nacional de Alfabetismo Funcional. Educação e Pesquisa, v34, n3, 2008.

TARTUCE, G. L. B. P. Balanço da produção de conhecimentos sobre educação não escolar de adultos: PLANFOR e educação do trabalhador, 1999-2006. Revista e-Curriculum (PUC-SP), v5, n1, 2009.

\section{Sobre os autores:}

Adriano Vargas Freitas: Professor da Universidade Federal Fluminense, Doutor em Educação Matemática pela PUC/SP.

Célia Maria Carolino Pires: Mestre em Matemática pela PUC-SP, doutrora em Educação pela USP. Atualmente é professora colaboradora da Universidade Federal do Mato Grosso do Sul.

Artigo recebido em novembro de 2014.

Artigo aprovado em abril de 2015. 